\title{
Case Report: Odontogenic carcinosarcoma arising from \\ ameloblastic fibrodentinoma with immunohistochemical
}

\section{profile [version 1; peer review: 2 not approved]}

\author{
Hend Mohammed Waguih Mahmoud Salem ${ }^{1,2}$, \\ Sarah Ahmed Mohamed Mahmoud Badawy (D), Hatem Wael Amer(i)2
}

${ }^{1}$ Basic Dental Services Department, Princess Nourah Bint Abdulrahman University, College of Dentistry, Riyadh

2Oral \& Maxillo-facial Pathology Department, Faculty of Dentistry, Cairo University, 11553

\section{V1 First published: 12 Jun 2020, 9:603 \\ https://doi.org/10.12688/f1000research.23969.1}

Latest published: $15 \operatorname{Dec} 2020, \mathbf{9 : 6 0 3}$

https://doi.org/10.12688/f1000research.23969.2

\section{Abstract}

Odontogenic carcinosarcoma is an extremely rare mixed malignant odontogenic neoplasm in which both the epithelial and the ectomesenchymal components are cytologically malignant. Owing to the scarcity of the reported cases, the clinical behavior of odontogenic carcinosarcoma remains unexplored. The present work reports a case of odontogenic carcinosarcoma of the mandible with the detailed immuno-histochemical profile. A 28-year-old male presented with a left painless swelling, which recurred after hemimandiblectomy of the lesion. Complete excision of the lesion with a wide safety margin was performed. The histopathological examination revealed cytological malignant features in the follicles as well as in the ectomesenchyme. The immuno-histochemistry demonstrated evidence of epithelial mesenchymal transition. After nine months, the patient demonstrated recurrence in the infra-temporal fossa. Odontogenic carcinosarcoma is a rare highly aggressive malignant odontogenic tumor. Positive expression of smooth muscle actin and vimentin in the epithelial component is a useful aid in the diagnosis of odontogenic carcinosarcoma.

\section{Keywords}

Odontogenic carcinosarcoma, a-smooth muscle actin, vimentin, epithelial mesenchymal transition, Ki-67.

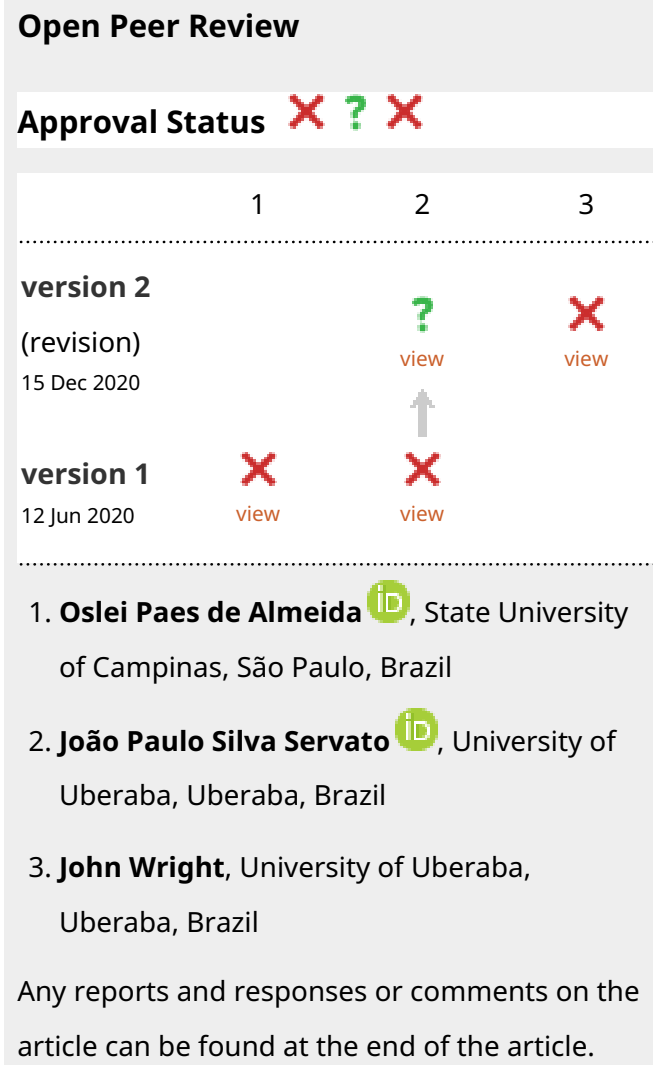

3

1. Oslei Paes de Almeida ID, State University

of Campinas, São Paulo, Brazil

2. João Paulo Silva Servato (iD), University of

Uberaba, Uberaba, Brazil

3. John Wright, University of Uberaba,

Uberaba, Brazil

Any reports and responses or comments on the article can be found at the end of the article.

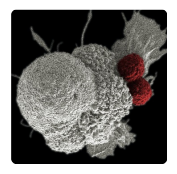

This article is included in the Oncology

gateway. 
Corresponding author: Sarah Ahmed Mohamed Mahmoud Badawy (sarah.badawy@dentistry.cu.edu.eg)

Author roles: Salem HMWM: Conceptualization, Funding Acquisition, Resources, Supervision, Writing - Review \& Editing; Ahmed Mohamed Mahmoud Badawy S: Conceptualization, Formal Analysis, Methodology, Project Administration, Software, Visualization, Writing - Original Draft Preparation; Amer HW: Data Curation, Investigation, Methodology, Supervision, Validation, Writing - Review \& Editing

Competing interests: No competing interests were disclosed.

Grant information: This research was funded by the Deanship of Scientific Research at Princess Nourah bint Abdulrahman University through the fast track Research Funding Program.

Copyright: ( 2020 Salem HMWM et al. This is an open access article distributed under the terms of the Creative Commons Attribution License, which permits unrestricted use, distribution, and reproduction in any medium, provided the original work is properly cited.

How to cite this article: Salem HMWM, Ahmed Mohamed Mahmoud Badawy S and Amer HW. Case Report: Odontogenic carcinosarcoma arising from ameloblastic fibrodentinoma with immunohistochemical profile [version 1; peer review: 2 not approved] F1000Research 2020, 9:603 https://doi.org/10.12688/f1000research.23969.1

First published: 12 Jun 2020, 9:603 https://doi.org/10.12688/f1000research.23969.1 


\section{Introduction}

Malignant odontogenic tumors are rare group of malignant neoplasms that arise from odontogenic remnants ${ }^{1}$. One of these neoplasms is odontogenic carcinosarcoma (OCS), an extremely rare mixed malignant odontogenic neoplasm in which both the epithelial and the ectomesenchymal components are cytologically malignant ${ }^{2}$. In the 1992 World Health Organization (WHO) classification of tumors, OCS was included in the malignant odontogenic tumors after Tanaka and co-workers (1991) first reported an odontogenic tumor with a mixture of malignant epithelial and ectomesenchymal components ${ }^{3}$. In the 2005 WHO classification, the tumor was removed due to an absence of current diagnostic criteria ${ }^{4}$. OCS has been added again in the 2017 edition because of the availability of cases with adequate diagnostic immunohistochemical and molecular criteria $^{5,6}$. Owing to the scarcity of reported cases - only eleven reported cases in the English literature - OCS clinical behavior remains unexplored ${ }^{7,8}$. In the current work, we report a case of OCS with the detailed clinical, radiographic, histopathological and immunohistochemical description.

\section{Case report}

A 28-year-old Egyptian male patient working as an accountant was referred to the Department of Oral and Maxillofacial Surgery, Faculty of Dentistry, Cairo University, with a complaint of painless swelling of six months duration in the left side of his face measuring $7 \times 6 \mathrm{~cm}$. The patient had a pathological report of an incisional biopsy, performed outside our institute, which was diagnosed as ameloblastoma. There were no palpable lymph nodes. Intra-oral examination revealed an absence of the lower left molars with a fistula opening on the alveolar crest with no oozing pus.
A cone beam computed tomography examination revealed an ill-defined multilocular osteolytic lesion with fine radiopacities extending from the lower left second premolar up to the ramus (Figure 1). A hemi-mandibulectomy was performed based on the incisional biopsy diagnosis and the pathological fracture of the mandible. The ramus was totally destructed and the tumor was invading the masseter muscle (Figure 2).

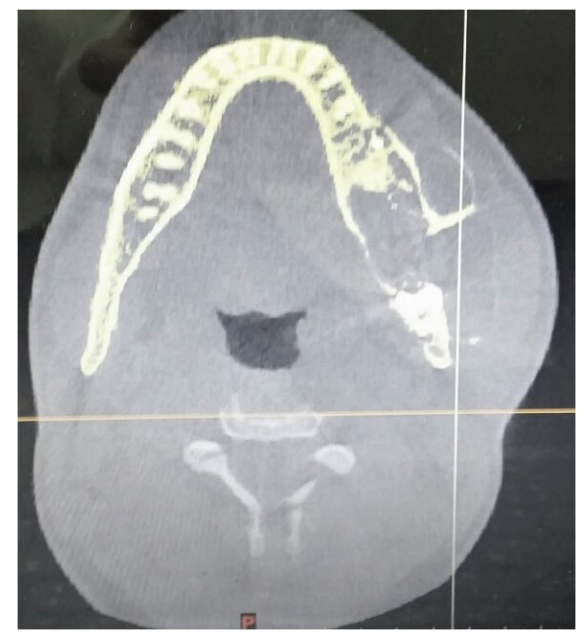

Figure 1. Cone beam computed tomography of odontogenic carcinosarcoma, axial view showing the multilocular lesion extending from the left lower second premolar to the condyle involving the whole ramus with buccal perforation. There was scattered radiopacities closely related to the impacted first molar. The second molar was displaced against the angle of the mandible.
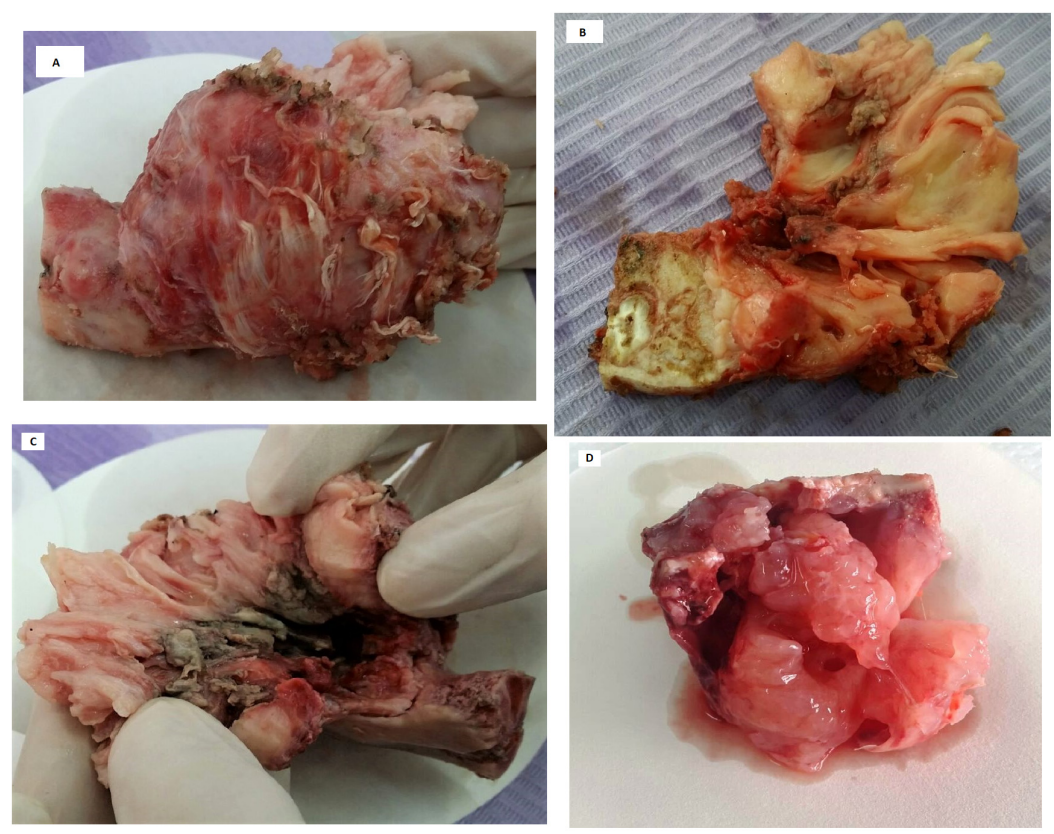

Figure 2. Gross examination: (A) Hemi-mandibulectomy with safety margin including the masseter muscle. (B) Cross-section of the resected specimen showing the fleshy neoplasm and the impacted first molar. (C) Top view of the resected specimen showing the necrotic fistula on the alveolar ridge. (D) The excisional specimen of the recurred lesion. 
Differential diagnosis was made based on the clinical examination, radiographic appearance and gross examination as: ghost cell odontogenic carcinoma, ameloblastic carcinoma, ameloblastic fibrosarcoma, ameloblastic carcinosarcoma, calcifying epithelial odontogenic tumor, atypical type of ameloblastic fibrodentinoma ${ }^{9}$ and ameloblastoma.

Histopathological examination revealed follicles of odontogenic epithelium that were compressed by highly cellular hyalinized primitive connective tissue resembling dental papilla. The epithelial cells showed little pleomorphism and hyperchromatism. In some fields, dentinoid matrix was detected around the epithelial strands (Figure 3). Based on the histopathological examination, a diagnosis was made of ameloblastic fibrodentinoma (atypical type).

After nine months, the patient returned with another large painless swelling in the left temporal and infra-temporal fossa that had appeared three months previously. An oral and maxillofacial surgeon used local anesthesia and an intra-oral approach to completely excise the recurrent lesion (Figure 2D). Augmentin 1gm tablet/12 hours for five days and antiinflammatory medication were prescribed for the patient after the surgery. Histopathological examination revealed highly cellular neoplasm, which showed cellular atypia and increased mitosis in both epithelial and ectomesenchymal components (Figure 4).

The epithelial nests showed strong membranous positivity with AE1/AE3, while vimentin stained the ectomesenchyme diffusely and the epithelial nests patchily. Alpha-smooth muscle actin ( $\alpha$-SMA) showed positivity in the endothelial cells as well as in scattered epithelial and ectomesenchymal cells. Ki67 index was around $40 \%$ in the epithelial component, while in the ectomesenchymal component it was around 12\% (Figure 5).
Based on the histopathological and immunohistochemical findings, the case was diagnosed as OCS arising from ameloblastic fibrodentinoma. The patient was missed for the follow-up appointment after the last excision of the lesion and could not be reached for further follow-up.

\section{Discussion}

OCS is a rare biphasic malignant odontogenic neoplasm that has the same architecture of ameloblastic fibroma, in which the epithelial and the ectomesenchymal components are cytologically malignant. It can develop de novo from odontogenic remnants or as a transformation from a preexisting odontogenic benign or malignant neoplasm ${ }^{6}$. This transformation may be attributed to multiple surgical procedures or recurrences of the neoplasm ${ }^{2}$. The present case arose from a preexisting ameloblastic fibrodentinoma. To the best of our knowledge, this is the first reported case of OCS to arise from ameloblastic fibrodentinoma. Kunkel et al. (2004), DeLair et al. (2007) and Chikosi et al. (2011) reported cases aroused from ameloblastic fibrosarcoma, ameloblastic fibroma and ameloblastoma, respectively $2,10,11$.

Our case was a 28-year-old male with the lesion affecting the posterior mandible. In the English literature, there was only one case that occurred in maxilla ${ }^{4}$. The most common radiographic picture of OCS is ill-defined multilocular radiolucency with cortical perforation ${ }^{6}$. The current case showed multiple radiopacities owing to the preexisting ameloblastic fibrodentinoma.

OCS must be distinguished from ameloblastic fibrosarcoma, in which the ectomesenchymal component only shows cellular atypia, and spindle cell variant of ameloblastic carcinoma, which lacks the ectomesenchymal component ${ }^{2-8}$. In the present case, there was a patchy positive expression of vimentin in the
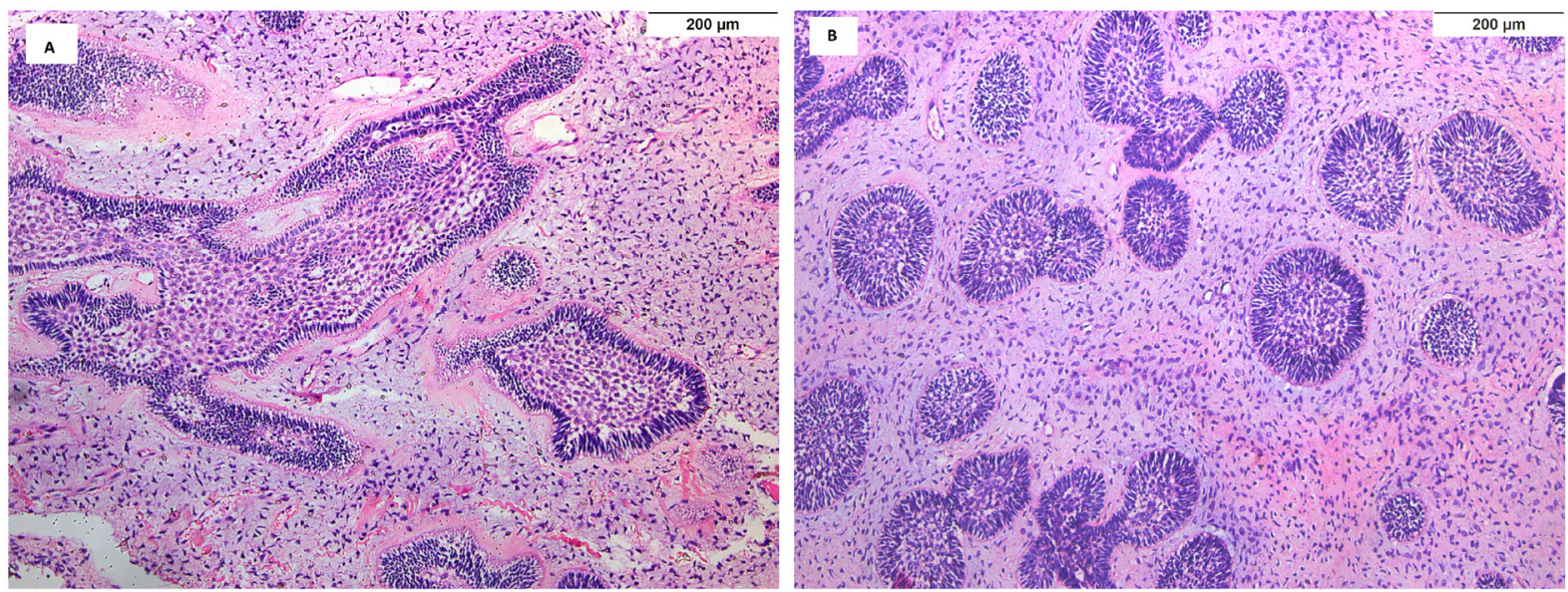

Figure 3. Histopathological examination of the resected specimen (hematoxylin and eosin stain, X100). (A) Microscopic image showing odontogenic epithelial follicles formed of ameloblast-like cells on the periphery and stellate-reticulum like cells on the center, which were surrounded by primitive ectomesenchyme resembling dental papilla. Dentinoid material was detected in contact with the epithelial follicles. (B) Microscopic image showing another field which was hypercellular in both components with mild pleomorphism and hyperchromatism. 


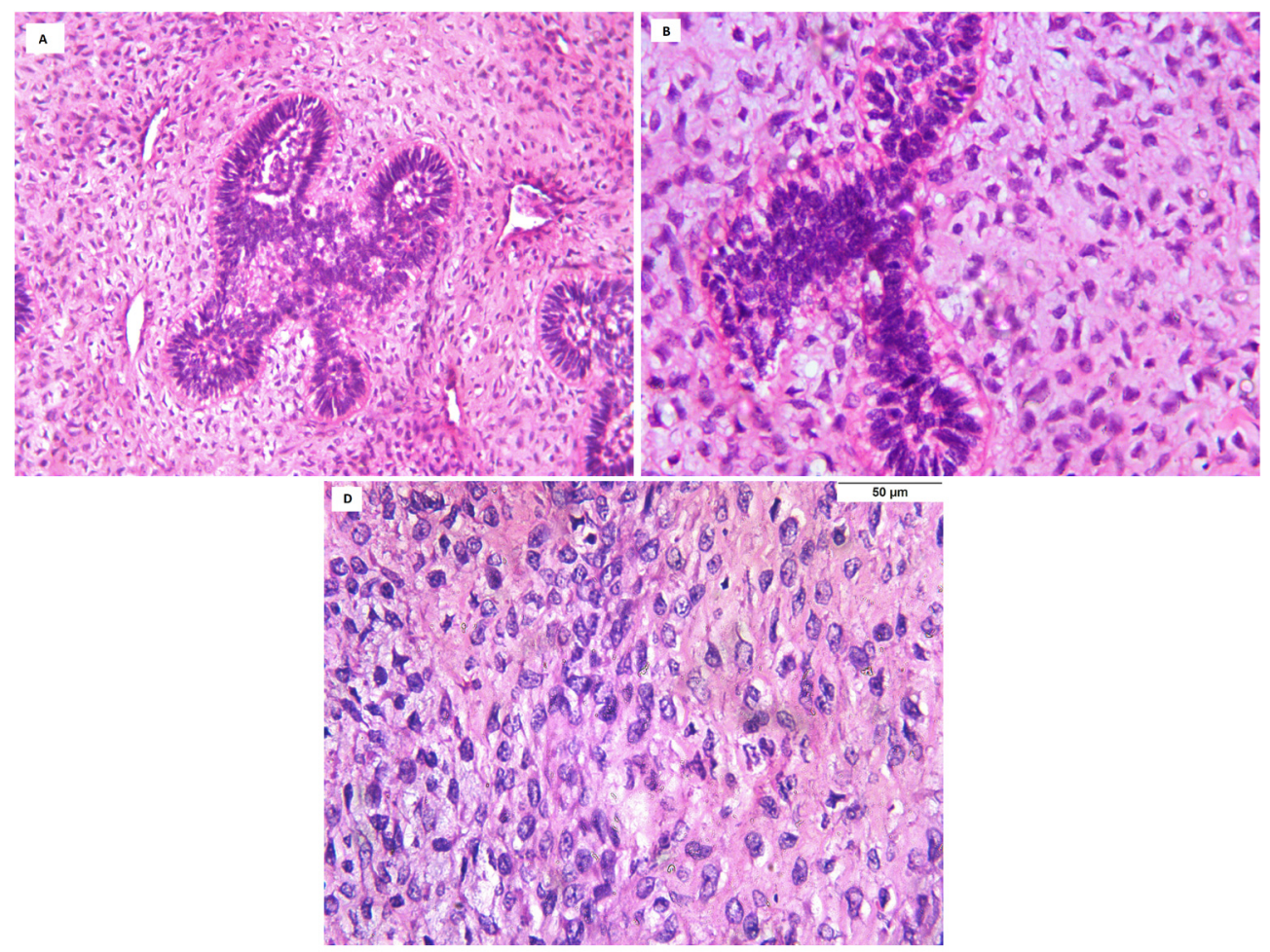

Figure 4. Histopathological examination of the recurred lesion (hematoxylin and eosin stain). (A) Microscopic image showing hypercellular epithelial follicles along with hypercellular ectomesenchyme (X100). (B) Microscopic image showing pleomorphism, hyperchromatism, increased mitosis and increased nuclear-cytoplasmic ratio (X400). (C) Microscopic image showing atypia in ectomesenchymal component with increased mitosis and abnormal mitotic figures (X400).
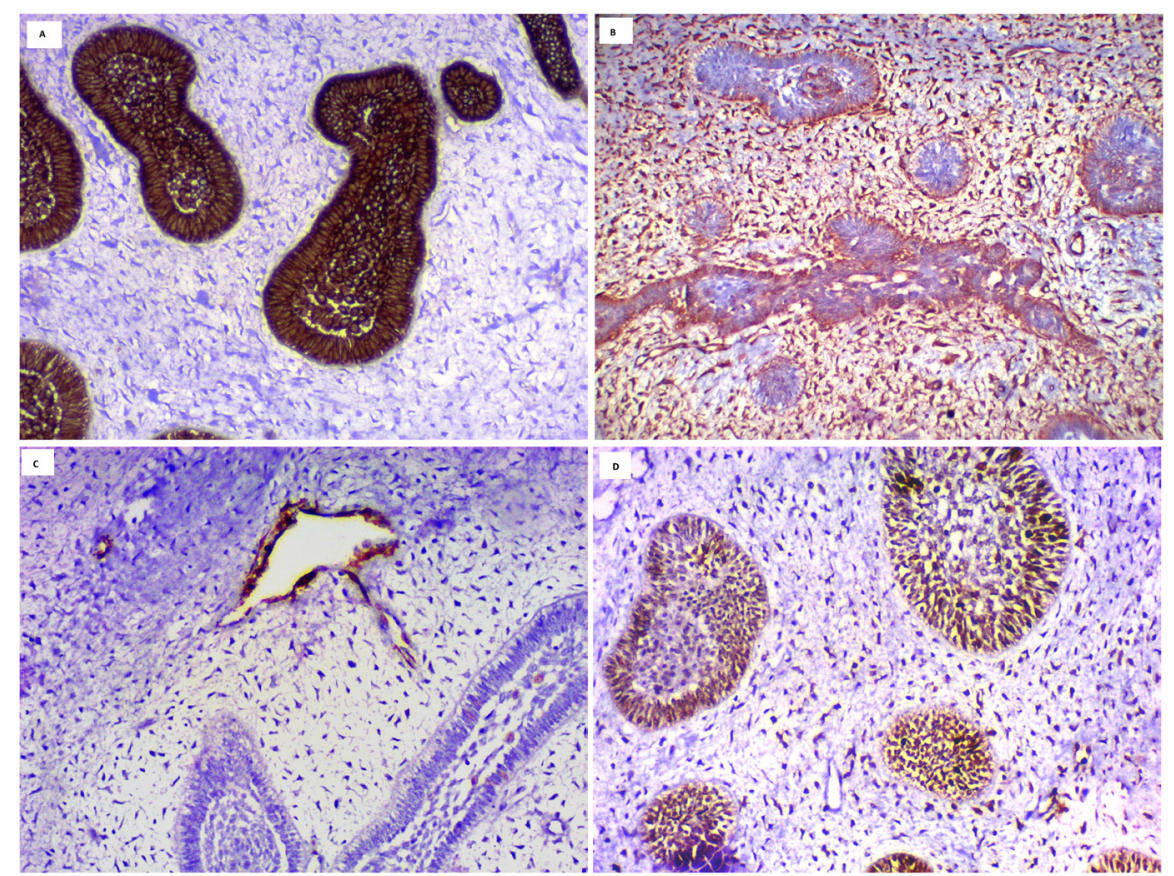

Figure 5. Immunohistochemical staining (X200). (A) Microscopic image showing strong membranous expression of AE1/AE3 in the epithelial component. (B) Microscopic image showing strong diffuse cytoplasmic expression of vimentin in ectomesenchymal component along with patchy expression in the epithelial component. (C) Microscopic image showing cytoplasmic expression of $\alpha$-SMA in the endothelial cells and scattered epithelial and ectomesenchymal cells. (D) Microscopic image showing high nuclear expression of Ki-67 in both epithelial and ectomesenchymal components. 
epithelial component. This could be explained as OCS undergoes epithelial mesenchymal transition, a process in which the polarized immotile epithelial cell changes to gain the mesenchymal phenotype and indicates more aggressive behavior of the neoplasm ${ }^{7,12,13}$.

In accordance with Dos Santos et al. (2018), $\alpha$-SMA staining in the current case showed scattered cytoplasmic staining in both the ectomesenchymal and epithelial cells ${ }^{4}$. Its expression in the ectomesenchymal cells could be attributed to the emergence of cancer associated myofibroblasts, which play a significant role in tumor progression and the epithelial mesenchymal transition process, explaining $\alpha$-SMA expression in the epithelial cells ${ }^{14}$.

The proliferative index $\mathrm{Ki}-67$ in our case was around $40 \%$ in the epithelial component and $12 \%$ in the ectomesenchymal component. This is in accordance with the work of Dos Santos et al. (2018) and Soares et al. (2019), who found that Ki-67 index was higher in the epithelial component than the ectomesenchymal component ${ }^{4-7}$.

The principle line of treatment, as with other malignant odontogenic neoplasms, is surgical resection with a wide safety margin along with neck dissection. However, adjunctive radiotherapy is still a matter of question, and it may be helpful in cases with soft tissue invasion ${ }^{6}$.

\section{Conclusion}

OCS is an extremely rare odontogenic malignant neoplasm that shows very aggressive clinical behavior with multiple recurrences and possible metastasis. Immunohistochemical staining with vimentin, $\alpha$-SMA and $\mathrm{Ki}-67$ is helpful in the diagnosis of OCS.

\section{Data availability}

All data underlying the results are available as part of the article and no additional source data are required.

\section{Consent}

Written informed consent for publication of their clinical details or clinical images was obtained from the patient.

\section{Acknowledgments}

This research was funded by the Deanship of Scientific Research at Princess Nourah bint Abdulrahman University through the fast track Reaseach Funding Program. Moreover, we are sincerely grateful for our colleges in Oral \& Maxillofacial Surgery department, Faculty of Dentistry, Cairo University.
1. El-Naggar AK, Chan JKC, Grandis JR, et al.: WHO Classification of Head and Neck Tumours. 4th edition, Lyon: IARC Press; 2017; 9: 213.

Reference Source

2. DeLair D, Bejarano PA, Peleg M, et al:: Ameloblastic carcinosarcoma of the mandible arising in ameloblastic fibroma: a case report and review of the literature. Oral Surg Oral Med Oral Pathol Oral Radiol Endod. 2007; 103(4): 516-520. PubMed Abstract | Publisher Full Text

3. Tanaka $\mathrm{T}$, Ohkubo T, Fujitsuka $\mathrm{H}$, et al:: Malignant mixed tumor (malignant ameloblastoma and fibrosarcoma) of the maxilla. Arch Pathol Lab Med. 1991 115(1): 84-87.

PubMed Abstract

4. Dos Santos JN, Servato JPS, Cardoso SV, et al.: Odontogenic carcinosarcoma: morphologic and immunohistochemical description of a case. Oral Surg Oral Med Oral Pathol Oral Radiol. 2018; 126(5): e264-e270. PubMed Abstract | Publisher Full Text

5. Soluk-Tekkesin M, Wright JM: The World Health Organization Classification of Odontogenic Lesions: A Summary of the Changes of the 2017 (4th) Edition. Turk Patoloji Derg. 2018; 34(1)

PubMed Abstract | Publisher Full Text

6. Schuch LF, de Arruda JAA, Silva LVO, et al: Odontogenic carcinosarcoma: A systematic review. Oral Oncol. 2018; 85: 52-59.

PubMed Abstract | Publisher Full Text

7. Soares CD, Delgado-Azañero W, Morais TMDL, et al:: Odontogenic Carcinosarcoma: Clinicopathologic Features of 2 Cases. Int J Surg Pathol. 2020; 28(4): 421-426.

PubMed Abstract | Publisher Full Text
8. Kim IK, Pae SP, Cho HY, et al:: Odontogenic carcinosarcoma of the mandible: a case report and review. J Korean Assoc Oral Maxillofac Surg. 2015; 41(3): 139-144. PubMed Abstract | Publisher Full Text | Free Full Text

9. Giraddi GB, Garg V: Aggressive atypical ameloblastic fibrodentinoma: Report of a case. Contemp Clin Dent. 2012; 3(1): 97-102. PubMed Abstract | Publisher Full Text | Free Full Text

10. Kunkel M, Ghalibafian M, Radner $\mathrm{H}$, et al.: Ameloblastic fibrosarcoma or odontogenic carcinosarcoma: a matter of classification? Oral Oncol. 2004; 40(4): 444-449.

PubMed Abstract | Publisher Full Text

11. Chikosi R, Segall N, Augusto $P$, et al.: Odontogenic carcinosarcoma: case report and literature review. J Oral Maxillofac Surg. 2011; 69(5): 1501-1507. PubMed Abstract | Publisher Full Text

12. McLean-Holden AC, Bishop JA, Kessler HP, et al:: Spindle-cell variant of ameloblastic carcinoma: a report of 3 cases and demonstration of epithelialmesenchymal transition in tumor progression. Oral Surg Oral Med Oral Pathol Oral Radiol. 2019; 128(3): e113-e121. PubMed Abstract | Publisher Full Text

13. Bello IO, Alanen K, Slootweg PJ, et al.: Alpha-smooth muscle actin within epithelial islands is predictive of ameloblastic carcinoma. Oral Oncol. 2009; 45(9): 760-5.

PubMed Abstract | Publisher Full Text

14. Mahmoud SAM, Amer HW, Mohamed SI: Primary ameloblastic carcinoma: literature review with case series. Pol J Pathol. 2018; 69(3): 243-253. PubMed Abstract | Publisher Full Text 


\section{Open Peer Review}

\section{Current Peer Review Status: $\mathrm{X} \times$}

\section{Version 1}

Reviewer Report 30 September 2020

https://doi.org/10.5256/f1000research.26443.r69312

(c) 2020 Servato J. This is an open access peer review report distributed under the terms of the Creative Commons Attribution License, which permits unrestricted use, distribution, and reproduction in any medium, provided the original work is properly cited.

\section{João Paulo Silva Servato}

University of Uberaba, Uberaba, Brazil

1) Is the background of the case's history and progression described in sufficient detail?

Partly - In reason to understand OCS progression and outcomes, more follow up details should be addressed.

Moreover, the authors should attend to the new WHO classification nomenclature. As stated by Speight PM, and Takata T., 2018: "the ameloblastic fibrodentinoma and ameloblastic fibroodontoma have been removed as distinct entities"1. In this way, the nomenclature should be reviewed.

2) Are enough details provided of any physical examination and diagnostic tests, treatment given and outcomes?

No - Please, improve the details in histopathological and immunohistochemical profile.

2.1) High power field images is needed to improve the recognition of the main expected features, as described by El-Mofty, S. K., in the 2017 WHO blue book "The cells in the sarcomatous component are markedly pleomorphic, with enlarged and bizarre nuclei and occasional multinucleation and mitosis. The epithelial component is frankly malignant, with large hyperchromatic nuclei and an increased N:C ratio. The typical ameloblastic features such as peripheral nuclear palisading and inner stellate reticulum may be lost focally." ${ }^{2}$

In the same way, Ki-67 images must be improved to clearly demonstrate the high levels of Ki-67 tagging in both epithelial and mesenchymal components.

3) Is sufficient discussion included of the importance of the findings and their relevance to future understanding of disease processes, diagnosis or treatment?

Partly, the discussion section should be expanded to access the relevance of this case in the 
understand of OCS main epidemiological characteristics, histopathological features, the biological profile and its prognosis/ behavior.

Moreover, as describe in CARE guidelines, this section must describe:

a) Strengths and limitations in your approach to this case.

b) The rationale for your conclusions.

c) The primary "take-away" lessons from this case report.

4) Is the case presented with sufficient detail to be useful for other practitioners?

No, since it do not attended to most recent WHO classification and to CARE guidelines.

\section{References}

1. Speight PM, Takata T: New tumour entities in the 4th edition of the World Health Organization Classification of Head and Neck tumours: odontogenic and maxillofacial bone tumours.Virchows Arch. 2018; 472 (3): 331-339 PubMed Abstract | Publisher Full Text

2. El-Naggar AK, Chan JKC, Grandis JR, et al.: WHO Classification of Head and Neck Tumours. IARC Press. 2017; 9: 213

3. Wright JM, Vered M: Update from the 4th Edition of the World Health Organization Classification of Head and Neck Tumours: Odontogenic and Maxillofacial Bone Tumors. Head Neck Pathol. 2017; 11 (1): 68-77 PubMed Abstract | Publisher Full Text 4. Soares CD, Delgado-Azañero W, Morais TML, de Almeida OP, et al.: Odontogenic Carcinosarcoma: Clinicopathologic Features of 2 Cases.Int J Surg Pathol. 2020; 28 (4): 421-426

PubMed Abstract | Publisher Full Text

Is the background of the case's history and progression described in sufficient detail? Partly

Are enough details provided of any physical examination and diagnostic tests, treatment given and outcomes?

No

Is sufficient discussion included of the importance of the findings and their relevance to future understanding of disease processes, diagnosis or treatment?

Partly

Is the case presented with sufficient detail to be useful for other practitioners? No

Competing Interests: No competing interests were disclosed.

Reviewer Expertise: Oral and maxillofacial pathology; Oral medicine; Immunology.

I confirm that I have read this submission and believe that I have an appropriate level of expertise to state that I do not consider it to be of an acceptable scientific standard, for reasons outlined above. 
Author Response 15 Dec 2020

\section{Sarah Ahmed Mohamed Mahmoud Badawy}

First, we can't thank you enough for your sincere and detailed review. We made a second version of the article with the revisions you recommended in your review; as follow:

We did contact the surgeon to collect more details about the follow-up of the patient.

We changed the nomenclature of " ameloblastic fibrodentinoma" as you recommended, and clarified the reason why we diagnosed it like that.

We changed and added histopathological figures as you recommended with more detailed interpretation.

We repeated the ki67 staining and analysed it with the image analyser Leica QWin software.

We tried to improve the discussion part as you recommended to follow CARE guidelines.

We hope that our revisions meet your expectations. Again, thank you for your precious time.

Competing Interests: No competing interests

Reviewer Report 18 August 2020

\section{https://doi.org/10.5256/f1000research.26443.r65932}

(C) 2020 de Almeida O. This is an open access peer review report distributed under the terms of the Creative Commons Attribution License, which permits unrestricted use, distribution, and reproduction in any medium, provided the original work is properly cited.

\section{Oslei Paes de Almeida}

Diagnosis Department, Oral Pathology Section, Dentistry Faculty of Piracicaba, State University of Campinas, São Paulo, Brazil

I read this article and below are my comments for the journal:

Based on documentations included in the article some points should be reconsidered by the authors.

Diagnosis of ameloblastic fibrodentinoma does not seem to be correct, dentinoid material is not evident.

Possibly from the beginning the lesion is an ameloblastic fibrosarcoma, therefore the microscopical aspects should be carefully reviewed including a Ki-67 staining.

Diagnosis of carcinosarcoma should be reconsidered and most immune reactions repeated and reanalysed, including Ki-67. Interpretation of some reactions does not seem to be appropriate. 
Is the background of the case's history and progression described in sufficient detail? No

Are enough details provided of any physical examination and diagnostic tests, treatment given and outcomes?

No

Is sufficient discussion included of the importance of the findings and their relevance to future understanding of disease processes, diagnosis or treatment?

No

Is the case presented with sufficient detail to be useful for other practitioners?

No

Competing Interests: No competing interests were disclosed.

Reviewer Expertise: Oral Pathology.

I confirm that I have read this submission and believe that I have an appropriate level of expertise to state that I do not consider it to be of an acceptable scientific standard, for reasons outlined above.

Author Response 08 Sep 2020

Sarah Ahmed Mohamed Mahmoud Badawy

First of all, thank you for your review. I hope that in my response, I will be able to clarify some points:

The diagnosis of the first biopsy was based on the presence of dentinoid material which is evident in figure 3.A.

Moreover, both the ectomesenchymal and the epithelial compartments in the first biopsy showed little cellular activity without cellular atypia in all fields, there was no way to consider it as a malignancy back then without histopathological evidence; even if the clinical behavior was doubted.

The immunohistochemical reaction of Ki67 was interpreted with 3 pathologists last, I wished you can mention clearly what the details do you need us to clarify in the sections of case history, physical examination, investigations, and discussion? Thank you for your time.

Competing Interests: No competing interests were disclosed. 
The benefits of publishing with F1000Research:

- Your article is published within days, with no editorial bias

- You can publish traditional articles, null/negative results, case reports, data notes and more

- The peer review process is transparent and collaborative

- Your article is indexed in PubMed after passing peer review

- Dedicated customer support at every stage

For pre-submission enquiries, contact research@f1000.com 